\title{
Outcomes of the National Head and Neck Cancer Awareness and Screening Campaign in Oman
}

\section{نتائج الحملة الوطنية للتوعية بسرطان الرأس والعنق وفحصه في سلطنة عُمان}

زينة الذهلية، سالمة محمد الشيبانية، فيصل الكلباني، جميل حيدر

\begin{abstract}
Objectives: The prognosis of head and neck cancer (HNC) depends substantially on disease stage at the time of diagnosis. Unfortunately, the majority of HNC patients present at relatively late stages. In Oman, a national screening campaign was conducted to increase public awareness of HNC and encourage early detection. This study aimed to report the outcomes of that campaign. Methods: The campaign took the form of biannual events conducted at a tertiary care centre and in public malls in Muscat, Oman from April 2015 to July 2019. Data were collected from participants using the Head and Neck Cancer Alliance screening form. Otolaryngologists and oral maxillofacial surgeons performed a thorough physical evaluation of the head and neck region. Results: Of the 1,500 individuals visiting the hospital and malls during the campaign events, a total of 509 agreed to undergo screening (response rate: $33.9 \%$ ). Of these, $12.8 \%$ had positive screening results and $5.9 \%$ required further evaluation. However, none of the cases with suspicious findings were found to be malignant after a thorough evaluation. Overall, $16.9 \%$ of the participants were aware of the early signs of HNC; in addition, 5.5\% knew how to perform an oral self-examination. Conclusion: Screening is a simple and safe method for the prevention and early detection of HNC. Mass screening and public awareness programmes may help to reduce the burden of this disease in Oman.
\end{abstract}

Keywords: Head and Neck Cancer; Early Detection of Cancer; Mass Screening; Knowledge; Health Risk Behaviors; Oman.

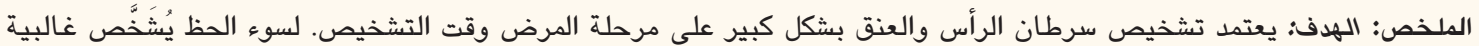

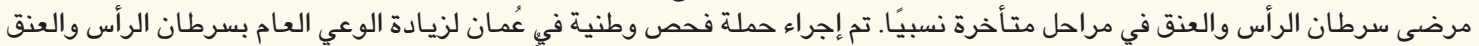

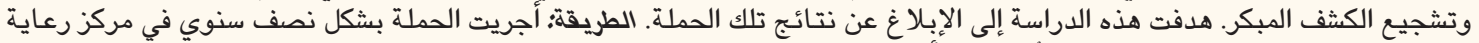

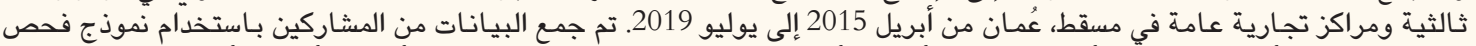

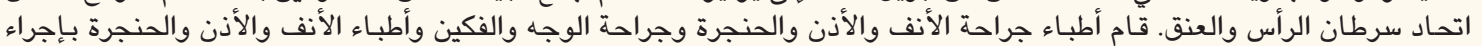

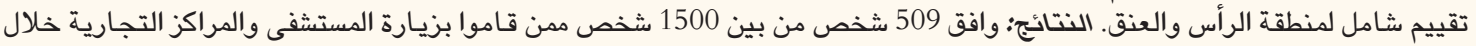

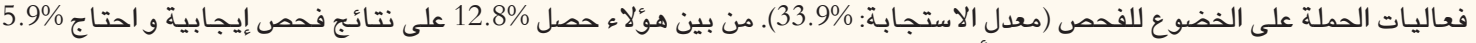

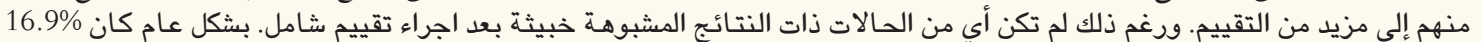

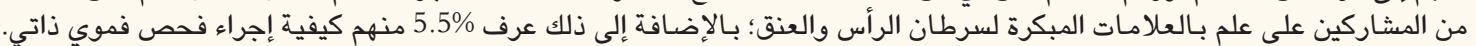

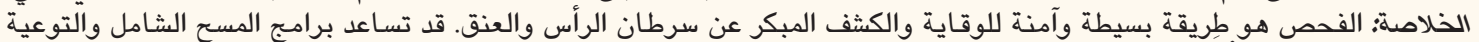
العامة على تخفيف وَطْأة هذا المرض فيقة في سلطنة عُمَان. الكلمات المفتاحية؛ سرطان الرأس والعنق؛ الكثثف المبكر عن السرطان؛ المسح الشامل؛ المعرفة؛ سلوكيات المخاطر الصحية؛ سلطنة عُمَان.

\section{AdVANCES IN KNOWLEDGE}

This study describes outcomes from the first national head and neck cancer (HNC) screening campaign conducted in Oman and establishes baseline data for the Omani population.

In addition, this study assessed the level of awareness among the general population with regards to early HNC symptoms and signs.

\section{Application to Patient Care}

This study assessed the prevalence of HNC risk factors in the Omani population. Such information is of paramount importance for otolaryngologists and other physicians in the country.

The campaign emphasised the importance of self-examination among participants; such methods may help HNC cases be diagnosed at an earlier stage, thereby improving patient prognosis and reducing the burden on the local healthcare system.

$\mathrm{H}$ EAD AND NECK CANCER (HNC) IS THE sixth most common cancer globally and includes cancers of the upper aerodigestive tract (i.e. the oral cavity, oropharynx, nasopharynx and larynx), the nasal and paranasal sinuses and the salivary glands. ${ }^{1,2}$ Worldwide, there are 550,000 new HNC cases diagnosed per year. ${ }^{1}$ In Muscat, the capital city of Oman, the incidence of HNC was 4.3 cases per 
100,000 individuals in $2014 .{ }^{3}$ Overall, the prognosis of HNC depends upon the time of onset and the type and staging of the disease at presentation. The average five-year survival rate is $80 \%$ for early $\mathrm{HNC}$; however, this decreases to $30 \%$ if regional or distant metastasis is present. 4,5

It was observed by the authors that patients with HNC, particularly those with cancers of the oral cavity, usually presented at an advanced stage. Generally, the management of advanced stage HNC is complex, costly and results in poor outcomes, with many resources wasted on molecular studies that are non-reproducible and not applicable to the majority of patients. ${ }^{6}$ Underlying factors exacerbating the late presentation of cases include a lack of awareness regarding the signs, symptoms and risk factors for HNC within the general community as well as inadequate preventative and early detection measures on the part of healthcare providers. ${ }^{\text {? }}$

In contrast, screening programmes are comparatively cheaper and have been shown to play a key role in ensuring the early detection of affected patients worldwide. ${ }^{4,8-12}$ Moreover, because such programmes can detect cancerous or pre-cancerous lesions in the early stages, thus allowing a more timely management, they indirectly help to improve treatment outcomes and survival rates. ${ }^{13,14}$ In addition, these programmes serve to increase awareness of cancer symptoms among the general population. ${ }^{13,15}$ In 2005, the World Health Organization recommended that preventative programmes be implemented to combat the huge number of neglected patients with oral cancer. ${ }^{16}$ This study aimed to report the outcomes of the first HNC awareness and screening campaign conducted in Oman.

\section{Methods}

A national HNC screening and awareness campaign was conducted by the Departments of Ear, Nose \& Throat (ENT) and Head \& Neck Surgery at Al-Nahdha Hospital in Muscat, Oman. The campaign took the form of biannual events conducted in the months of April and July over a five-year period. The April event, known as Oral Head and Neck Cancer Awareness Day, was conducted on an annual basis from 2015 until 2019, while the July event was conducted yearly from 2016 to 2018 in recognition of World Head and Neck Cancer Day.

Each event was conducted at both Al-Nahdha Hospital and several public malls in Muscat in order to target patients and their relatives attending outpatient clinics as well as members of the general population. Individuals who were under 10 years old and those who had a recent history of infections (i.e. upper respiratory tract infections) or who were undergoing chemoradiation for any type of malignancy were excluded from the screening.

Data were collected using the Head and Neck Cancer Alliance screening form. ${ }^{17}$ This questionnaire provided data regarding the participants' demographic characteristics, health behaviours (i.e. smoking status and alcohol consumption), family or personal history of HNC, current symptoms and level of awareness regarding HNC symptoms and signs. Subsequently, each participant underwent a thorough physical examination by trained otolaryngologists and oral maxillofacial surgeons, focusing on the skin of the head and neck, ears, nose, oral cavity, oropharynx, larynx and salivary and thyroid glands. A rigid nasal endoscope and fibreoptic laryngoscope was also utilised to examine non-visualised areas in the nose, nasopharynx, oropharynx and larynx. ${ }^{18}$ Participants with positive findings were subsequently given a follow-up appointment at the Head and Neck Clinic at Al-Nahdha Hospital or at another related clinic for further evaluation. Those who were found to have suspicious lesions were followed up at outpatient clinics, with the results of the clinical assessment obtained from their medical records.

In terms of education awareness, participants were provided with printed leaflets regarding the risk factors and symptoms of head HNC as well as audio-visual materials on how to perform a selfexamination of the head and neck area. Furthermore, heath educators and volunteers from the Oman

Table 1: Symptoms identified during a five-year biannual national head and neck cancer screening campaign conducted in Oman $(\mathrm{N}=509)$

$\begin{array}{lcc}\text { Symptom } & \mathbf{n}(\%) & \mathbf{9 5 \%} \mathbf{C I} \\ \text { Voice changes } & 43(8.4) & 6.2-11.2 \\ \text { Sore throat } & 65(12.8) & 10-16 \\ \text { Mouth sore } & 26(5.1) & 3.4-7.4 \\ \text { Bleeding } & 39(7.7) & 5.5-10.3 \\ \text { Lump in throat } & 8(1.6) & 0.7-3.1 \\ \text { Tooth or gum problems } & 107(21) & 17.6-24.8 \\ \text { Earache } & 46(9) & 6.7-11.9 \\ \text { Difficulty swallowing } & 16(3.1) & 1.8-5.1 \\ \text { Growth in neck } & 13(2.6) & 1.4-4.3 \\ \text { Swelling in the head and/or neck } & 25(4.9) & 3.2-7.2 \\ \text { Dental problems } & 29(5.7) & 3.8-8.1 \\ \begin{array}{l}\text { Red or white patches in the } \\ \text { mouth }\end{array} & 23(4.5) & 2.9-6.7\end{array}$

$C I=$ confidence interval . 
Anti-Tobacco Society provided counselling services for interested participants. This included education regarding health risk behaviours such as diet, exercise, smoking and alcohol consumption.

Data regarding the participants' demographic characteristics, screening results and follow-up clinical assessment results underwent statistical analysis using the Statistical Package for the Social Sciences (SPSS), Version 21.0 (IBM Corp., Armonk, New York, USA). The biannual campaign was approved by the hospital administration as part of its community outreach services. Moreover, this study received ethical approval from the Research \& Ethics Committee at Al-Nahdha Hospital. Verbal consent was obtained from all subjects prior to screening.

\section{Results}

A total of 1,500 individuals attended either the AlNahdha Hospital as outpatients or visited malls during the course of campaign events conducted over a fiveyear period. Of these, 509 agreed to undergo HNC screening (response rate: 33.9\%). There were 321 males (63.1\%) and 188 females (36.9\%), resulting in a maleto-female ratio of $1.7: 1$. The mean age was $37 \pm 11.5$ years old (range: $11-76$ years).

Overall, 55 participants (10.8\%) were current tobacco users at the time of screening, of which 46 (83.6\%) reported smoking cigarettes and 27 (49.1\%) smoked both cigarettes and pipes. A total of 46 individuals (9\%) were ex-smokers and 13 (2.6\%) consumed alcohol. In terms of medical history, 82 participants (16.1\%) reported a family history of HNC, while three $(0.6 \%)$ had been previously treated for skin cancer.

Table 2: Anatomical site of suspicious lesions among cases requiring further evaluation identified during a five-year biannual national head and neck cancer screening campaign conducted in Oman $(\mathrm{N}=30)$

$\begin{array}{lc}\text { Site* } & \text { n (\%) } \\ \text { Skin } & 3(10) \\ \text { Ears } & 4(13.3) \\ \text { Nose } & 3(10) \\ \text { Oral cavity } & 7(23.3) \\ \text { Oropharynx } & 0(0) \\ \text { Larynx } & 4(13.3) \\ \text { Salivary glands } & 2(6.7) \\ \text { Thyroid gland } & 5(16.7) \\ \text { Neck } & 5(16.7) \\ \text { *The percentages do not add up to 100\% as some patients had multiple } \\ \text { suspicious lesions. }\end{array}$

During screening, the most common HNC symptoms observed were tooth or gum problems (21\%), followed by a sore throat (12.8\%) [Table 1]. A total of 65 participants $(12.8 \%)$ had positive examination findings, with 30 (5.9\%) requiring further evaluation; among those requiring further evaluation, a total of 33 suspicious lesions were recorded [Table 2]. Among the patients with suspicious lesions, there was an almost equal distribution among males and females (53.3\% versus $46.7 \%)$ and smokers and ex-smokers (16.7\% versus $13.3 \%$ ) [Table 3].

Of the 30 cases requiring further evaluation, 17 (56.7\%) presented for follow-up at a clinic. All cases were found to be negative for malignancy after a thorough evaluation. One participant had a lesion in the oral cavity that was excised, which histopathology subsequently revealed to be a squamous papilloma. Six participants with thyroid swelling underwent fineneedle aspiration cytology and ultrasonography; all were revealed to be benign lesions. Three participants were referred to the dermatology department for skin lesions.

Two participants had cervical lymphadenopathy and underwent appropriate investigations at another

Table 3: Characteristics of cases with suspicious lesions identified during a five-year biannual national head and neck cancer screening campaign conducted in Oman $(\mathrm{N}=509)$

\begin{tabular}{|c|c|c|}
\hline \multirow[t]{2}{*}{ Characteristic } & \multicolumn{2}{|c|}{ n (\%) } \\
\hline & $\begin{array}{l}\text { Cases with } \\
\text { suspicious lesions } \\
(\mathbf{n}=30)\end{array}$ & Total \\
\hline \multicolumn{3}{|l|}{ Gender } \\
\hline Female & $14(46.7)$ & $188(36.9)$ \\
\hline Male & $16(53.3)$ & $321(63.1)$ \\
\hline \multicolumn{3}{|l|}{ Age in years } \\
\hline$<45$ & $20(66.7)$ & $376(73.9)$ \\
\hline$\geq 45$ & $10(33.3)$ & $133(26.1)$ \\
\hline \multicolumn{3}{|l|}{ Smoking status } \\
\hline Smoker & $5(16.7)$ & $55(10.8)$ \\
\hline Ex-smoker & $4(13.3)$ & $46(9)$ \\
\hline Non-smoker & $21(70)$ & $408(80.2)$ \\
\hline \multicolumn{3}{|c|}{ Alcohol consumption } \\
\hline Yes & $1(3.3)$ & $13(2.6)$ \\
\hline No & $29(96.7)$ & $496(97.4)$ \\
\hline \multicolumn{3}{|c|}{ Family history of HNC } \\
\hline Yes & $6(20)$ & $82(16.1)$ \\
\hline No & 24. (80) & 427 (83.9) \\
\hline
\end{tabular}


hospital. One participant had a palpable level II cervical lymph node which improved following a course of antibiotics. One participant had a hard palate lesion which disappeared upon follow-up. Two participants had submandibular gland swellings and underwent sialendoscopies revealing ductal stenosis. One participant had pre-existing lung cancer that had been treated with radiotherapy; the screening identified an oral cavity lesion that was diagnosed as osteoradionecrosis and treated with debridement.

In terms of awareness, 86 participants (16.9\%) were aware of early signs of HNC compared to 423 participants (83.1\%) who were not aware. In addition, $5.5 \%$ knew how to perform an oral self-examination. The majority of the participants (90.6\%) reported an interest in volunteering to raise awareness of HNC.

\section{Discussion}

Up to 40,000 deaths from oral cancer can be prevented in high-risk individuals as a result of visual screening. ${ }^{19,20}$ Moreover, most HNC cases are preventable, with the two major risk factors being tobacco and alcohol consumption which account for approximately $75 \%$ of cases, with the effects of these risk factors being compounded in combination. ${ }^{21,22}$ Generally, patients with HNC present with a variety of symptoms depend on the site of lesion. However, early recognition of these symptoms and timely diagnosis and management greatly reduces the burden of this disease on the healthcare system. ${ }^{21,23-25}$

This study reported outcomes of the first national screening campaign conducted in Oman to screen for and establish the level of awareness of HNC signs and symptoms among the general public. In total, 509 participants were screened over a five-year period and underwent complete head and neck examinations. Of these, $22.4 \%$ constituted a high-risk population (i.e. smokers, ex-smokers and alcohol consumers). A small proportion (5.9\%) of the participants required further evaluation and were given follow-up appointments.

These findings were similar to those reported from other screening programmes. In the USA, Dwojak et al. found that $8 \%$ of Native Americans in South Dakota had positive HNC screening results. ${ }^{10}$ Similarly, Nunn et al. reported that $5.7 \%$ of Bangladeshi participants who received positive screening results in the UK were referred for further investigation. ${ }^{26}$ The majority of participants (56.7\%) with positive findings and required further evaluation in the present study attended their scheduled appointments. This rate of compliance was much higher in comparison to other screening programmes. Frenández Garotte et al. and O'Sullivan et al. reported follow-up compliance rates of $<30 \%$ and $33 \%$, respectively. ${ }^{13,15}$ It is likely that these findings indicate that the Omani campaign was successful in increasing awareness of HNC and the importance of its early detection. ${ }^{27}$

An interesting finding of the present study was that none of the participants in the screening campaign were found to have malignant disease. However, the reported detection rate for premalignant or malignant conditions during screening programmes is $<3 \%{ }^{4,23,28,29}$ Furthermore, participants in the current study were self-selected and most were not at particularly high risk of developing HNC; this may explain why there were no positive findings during the campaign. Indeed, previous studies have suggested that HNC screening programmes are more effective if they target populations who are at high risk. ${ }^{15,23}$ Shuman et.al. reported the outcomes of a screening campaign in which the many participants were smokers and alcohol consumers; a total of $47 \%$ had abnormal findings and $5 \%$ had suspicious lesions. ${ }^{23}$ During a screening campaign of residents at alcohol addiction treatment centres, O'Sullivan et.al. reported the prevalence of mucosal abnormalities to be $29 \%$ with 84 mucosal abnormalities/symptoms detected in 61 out of 220 subjects. ${ }^{15}$ The researchers concluded that oral cancer screening is an efficient and effective way of detecting potentially malignant lesions in highrisk individuals. ${ }^{15}$

Based on the findings of the current study, the level of knowledge among the Omani general population regarding the risk factors and signs and symptoms of HNC was low. Only $16.9 \%$ of the participants were aware of early signs of $\mathrm{HNC}$, with 83.1\% having never heard of HNC at all. Alarmingly, a similar lack of knowledge among both laypeople and healthcare personnel has been previously reported. ${ }^{26}$ In the present study, only $5.5 \%$ knew how to perform a self-examination of the oral cavity and head and neck region. Nevertheless, by the end of the campaign, the participants reported an increase in their awareness of HNC risk factors, symptoms and signs. Moreover, they had also learned an easy self-examination technique which they could practice on themselves and others and were strongly encouraged to share this information with their family and friends.

This study had several strengths. First, the screening was performed by trained otolaryngologists and oral maxillofacial surgeons. Second, the screening included a complete examination of the head and neck region and was not limited to the oral cavity as in other campaigns. ${ }^{30}$ Third, a rigid nasal endoscope and fibreoptic laryngoscope was utilised to examine non-visualised areas. ${ }^{18}$ Finally, the majority of the participants with positive findings were followed-up 
and evaluated at outpatient clinics after screening. On the other hand, the campaign was limited to Muscat and the results cannot be generalised to other areas of Oman. It is possible that people in other cities and rural areas would not demonstrate a similar level of awareness of HNC or its early symptoms and signs. In future, the national screening campaign will be extended to cover other regions of the country and will target high-risk populations to improve detection and awareness of this disease.

\section{Conclusion}

This study describes the outcomes of the first national HNC screening campaign conducted in Oman, establishing baseline data for the Omani population. Awareness and screening campaigns for $\mathrm{HNC}$ are a cost-effective, simple and non-invasive strategy to encourage early detection and increase community awareness of the disease and its related risk factors.

\section{CONFLICT OF INTEREST}

The authors declare no conflicts of interest.

\section{FUNDING}

No funding was received for this study.

\section{References}

1. Parkin DM, Bray F, Ferlay J, Pisani P. Global cancer statistics, 2002. CA Cancer J Clin 2005; 55:74-108. https://doi.org/10.33 22/canjclin.55.2.74.

2. Head and Neck Cancer Alliance. What are cancers of the head and neck? From: www.headandneck.org/types/ Accessed: Nov 2019.

3. Oman Ministry of Health. Cancer incidence in Oman: 2015. From: https://oca.om/wp-content/uploads/2019/01/CancerIncidence-in-Oman-2015.pdf Accessed: Nov 2019.

4. Gogarty DS, Shuman A, O'Sullivan EM, Sheahan P, Kinsella J, Timon C, et al. Conceiving a national head and neck cancer screening programme. J Laryngol Otol 2016; 130:8-14. https://doi.org/10.1017/S0022215115003084.

5. Jackson CR, Shuman AG, Hogikyan ND. A critical review of head and neck cancer screening. Eur J Clin Med Oncol 2011; 3:33-41.

6. Mignogna MD, Fedele S, Ruoppo E, Lo Russo L. The role of molecular techniques in preventing oral cancer and improving its poor prognosis: An illusion? J Oral Pathol Med 2002; 31:246-8. https://doi.org/10.1034/j.1600-0714.2002.310411.x.

7. Mignogna MD, Fedele S, Lo Russo L, Ruoppo E, Lo Muzio L. Oral and pharyngeal cancer: Lack of prevention and early detection by health care providers. Eur J Cancer Prev 2001; 10:381-3. https://doi.org/10.1097/00008469-200108000-00014.

8. Hapner ER, Wise JC. Results of a large-scale head and neck cancer screening of an at-risk population. J Voice 2011; 25:480-3. https://doi.org/10.1016/j.jvoice.2009.12.004.

9. Nakamura H. Biosensors: Monitoring human health for the SDGs Sustainable development goals. Biomed J Sci Tech Res 2018; 9:6953-6. https://doi.org/10.26717/BJSTR.2018.09.001761.
10. Dwojak S, Deschler D, Sargent M, Emerick K, Guadagnolo BA, Petereit D. Knowledge and screening of head and neck cancer among American Indians in South Dakota. Am J Public Health 2015; 105:1155-60. https://doi.org/10.2105/AJPH.2014.302177.

11. Nagao T, Warnakulasuriya S. Annual screening for oral cancer detection. Cancer Detect Prev 2003; 27:333-7. https://doi.org/1 0.1016/s0361-090x(03)00101-6.

12. Mathew B, Sankaranarayanan R, Sunilkumar KB, Kuruvila B, Pisani P, Nair MK. Reproducibility and validity of oral visual inspection by trained health workers in the detection of oral precancer and cancer. Br J Cancer 1997; 76:390-4. https://doi. org/10.1038/bjc.1997.396.

13. Frenández Garrote L, Sankaranarayanan R, Lence Anta JJ, Rodriguez Salvá A, Maxwell Parkin D. An evaluation of the oral cancer control program in Cuba. Epidemiology 1995; 6:428-31. https://doi.org/10.1097/00001648-199507000-00019.

14. Brocklehurst P, Kujan O, Glenny AM, Oliver R, Sloan P, Ogden G, et al. Screening programmes for the early detection and prevention of oral cancer. Cochrane Database Syst Rev 2010; 11:CD004150. https://doi.org/10.1002/14651858.CD004150.pub3.

15. O'Sullivan EM. Prevalence of oral mucosal abnormalities in addiction treatment centre residents in Southern Ireland. Oral Oncol 2011; 47:395-9. https://doi.org/10.1016/j.oraloncology.20 11.03.003.

16. Petersen PE. Strengthening the prevention of oral cancer: The WHO perspective. Community Dent Oral Epidemiol 2005; 33:397-9. https://doi.org/10.1111/j.1600-0528.2005.00251.x.

17. Head and Neck Cancer Alliance. Screening form. From: www.tmh. org/ /media/files/cancer/screeningform.pdf Accessed: Nov 2019.

18. Patton LL. The effectiveness of community-based visual screening and utility of adjunctive diagnostic aids in the early detection of oral cancer. Oral Oncol 2003; 39:708-23. https://doi.org/10.10 16/s1368-8375(03)00083-6.

19. Downer MC, Moles DR, Palmer S, Speight PM. A systematic review of measures of effectiveness in screening for oral cancer and precancer. Oral Oncol 2006; 42:551-60. https://doi.org/10.10 16/j.oraloncology.2005.08.006.

20. Mignogna MD, Fedele S. Oral cancer screening: 5 minutes to save a life. Lancet 2005; 365:1905-6. https://doi.org/10.1016/ S0140-6736(05)66635-4.

21. Sankaranarayanan R, RamadasK, TharaS, Muwong R, Thomas G, Anju G, et al. Long term effect of visual screening on oral cancer incidence and mortality in a randomized trial in Kerala, India. Oral Oncol 2013; 49:314-21. https://doi.org/10.1016/j. oraloncology.2012.11.004.

22. Kowalski LP, Franco EL, Torloni H, Fava AS, de Andrade Sobrinho J, Ramos G, et al. Lateness of diagnosis of oral and oropharyngeal carcinoma: Factors related to the tumour, the patient and health professionals. Eur J Cancer B Oral Oncol 1994; 30B:167-73. https://doi.org/10.1016/0964-1955(94)90086-8.

23. Shuman AG, Entezami P, Chernin AS, Wallace NE, Taylor JM, Hogikyan ND. Demographics and efficacy of head and neck cancer screening. Otolaryngol Head Neck Surg 2010; 143:353-60. https://doi.org/10.1016/j.otohns.2010.05.029.

24. Mehanna H, Paleri V, West CM, Nutting C. Head and neck cancer--Part 1: Epidemiology, presentation, and prevention. BMJ 2010; 341:c4684. https://doi.org/10.1136/bmj.c4684.

25. National Institute for Health and Care Excellence. Improving outcomes in head and neck cancers: Cancer service guideline [CSG6]. From: http://guidance.nice.org.uk/csghn/guidance/pdf/ English Accessed: Nov 2019.

26. Nunn H, Lalli A, Fortune F, Croucher R. Oral cancer screening in the Bangladeshi community of Tower Hamlets: A social model. Br J Cancer 2009; 101:S68-72. https://doi.org/10.1038/ sj.bjc. 6605394 
27. Conway DI, Hashibe M, Boffetta P; INHANCE consortium, Wunsch-Filho V, Muscat J, La Vecchia C, et al. Enhancing epidemiologic research on head and neck cancer: INHANCE - The international head and neck cancer epidemiology consortium. Oral Oncol 2009; 45:743-6. https://doi.org/10.1016/j.oralonco logy.2009.02.007

28. Hawkins RJ, Wang EE, Leake JL. Preventive health care, 1999 update: Prevention of oral cancer mortality. The Canadian Task Force on Preventive Health Care. J Can Dent Assoc 1999; 65:617.
29. Mishra GS, Bhatt SH. Novel program of using village health workers in early detection and awareness of head and neck cancers: Audit of a community screening program. Indian J Otolaryngol Head Neck Surg 2017; 69:488-93. https://doi. org/10.1007/s12070-017-1231-1.

30. Paleri V, Staines K, Sloan P, Douglas A, Wilson J. Evaluation of oral ulceration in primary care. BMJ 2010; 340:c2639. https://doi.org/10.1136/bmj.c2639. 